\title{
Recobrimentos de Poli (Tereftalato de Etileno) Depositados em Aço por Aspersão Térmica a Partir de Pós Obtidos em Diferentes Condições de Moagem
}

\author{
Luciana T. Duarte, Vanessa de F. C. Lins \\ Departamento de Engenharia Química, UFMG \\ César Mariano \\ Rhodia, Poços de Caldas, MG \\ José Roberto T. Branco, Magno P. Collares \\ Fundação Centro Tecnológico de Minas Gerais \\ Roberto Galery \\ Departamento de Engenharia de Minas, UFMG
}

\begin{abstract}
Resumo: Neste trabalho foram analisados recobrimentos de poli(tereftalato de etileno), PET, depositados em aço carbono através da técnica de aspersão térmica à combustão, e produzidos a partir de pós oriundos de processos de moagem, em moinho de bolas e de facas, de garrafas de PET pós-consumo. Algumas condições de moagem foram testadas, tendose obtido pós com diferentes características morfológicas. As características morfológicas dos pós e dos recobrimentos foram avaliadas por microscopia óptica e eletrônica, tendo-se observado que o recobrimento apresentava bolhas, provavelmente devido à degradação do polímero. Além disto, os recobrimentos produzidos, bem como as amostras de pó, foram caracterizados por espectroscopia na região do infravermelho, por calorimetria exploratória diferencial e através da determinação de viscosidade intrínseca em solução. Os resultados obtidos mostraram que é possível a produção de aço carbono recoberto com PET através da técnica de aspersão térmica, sendo que o grau de degradação, a morfologia e a distribuição granulométrica dos pós utilizados influenciaram significativamente as características e propriedades dos recobrimentos formados.
\end{abstract}

Palavras-chave: Poli(tereftalato de etileno), aspersão térmica, análise térmica, viscosidade intrínseca.

\section{Thermally Sprayed-Coated Carbon Steel Produced Using PET Powder Obtained under Different Grinding Conditions}

Abstract: The main purpose of this work was to study the production of a thermal spray coated poly(ethyleneterephthalate) (PET) steel. PET coatings were made of a thin grinding waste produced by a PET recycling company, and of a PET powder, which was obtained by grinding post-consumer beverage bottles. Some grinding conditions, using a ceramic ball mill, were studied. Scanning Electronic Microscopy (SEM) and optical microscopy (OM) were used in the study of powder and coating morphologies, and this analysis showed that PET coating presents bubbles due to polymer degradation. PET powder and coating characteristics were investigated using Differential Scanning Calorimetry (DSC) and measurements of intrinsic viscosity. It was observed that the powder morphology and the degradation and size distribution of the PET powder affect significantly the characteristics and properties of coatings.

Keywords: Poly(ethylene therephthalate), thermal spray, recycling, thermal analysis, intrinsic viscosity.

\section{Introdução}

Poli (tereftalato de etileno), PET, é um termoplástico polar, com elevadas estabilidade dimensional e temperatura de fusão, alta impermeabilidade a gases e resistência química a ácidos e solventes ${ }^{[1]}$. O PET foi introduzido no mercado brasileiro em 1988 e é um dos polímeros mais utilizados na atualidade, principalmente na fabricação de embalagens ${ }^{[2]}$. Do total de PET consumido no Brasil, somente cerca de $21 \%$ é efetivamente reciclado, apesar de o PET ser um dos componentes mais presentes no lixo plástico no Brasil ${ }^{[3]}$.

Neste contexto, o presente trabalho aborda justamente uma aplicação alternativa para garrafas pós-consumo 
de PET, como recobrimento superficial em aço carbono 1020, usando-se a técnica de aspersão térmica a combustão, ilustrada na Figura 1. Neste processo, à medida que as partículas, em um estado fundido ou semi-fundido, se chocam contra o substrato, são achatadas e se solidificam nos contornos superficiais, constituindo uma estrutura lamelar. Tal processo apresenta grande versatilidade, decorrente da gama de materiais que pode ser depositada. Além disto, substratos de diferentes materiais, formas e tamanhos podem ser recobertos.

No atual estado da arte, relativamente poucos polímeros têm sido empregados como recobrimentos, e os dados de literatura acerca do comportamento de partículas poliméricas durante o processo de aspersão térmica são ainda escassos ${ }^{[4]}$. Parâmetros críticos do processo devem ser desenvolvidos para cada polímero, devendo ser selecionados adequadamente para garantir máxima fusão e mínima degradação das partículas na chama ${ }^{[5,6]}$

Lima et al ${ }^{[7]}$ mostraram que a produção de recobrimentos de PET por aspersão térmica é viável, sendo que os conjugados PET-aço carbono apresentaram baixos coeficientes de fricção, revelando uma aplicação promissora deste material contra desgaste.

Durante o processo de aspersão térmica, as partículas são submetidas a uma atmosfera oxidante, a temperaturas elevadas. Esse ambiente favorece a ocorrência de degradação térmica ou de degradação por oxidação do PET. No primeiro caso, há somente quebra da cadeia principal do polímero, sem alteração da estrutura química, mas com redução da massa molar e conseqüente aumento dos grupos carboxílicos terminais. Por outro lado, na degradação por oxidação do PET, a cadeia principal sofre mudanças químicas, com formação de alguns produtos de reação ${ }^{[8-12]}$.

A clivagem térmica de ligações éster presentes no PET inicialmente resulta na formação de um grupo éster vinílico terminal e em um grupo carboxílico terminal, conforme mostrado abaixo ${ }^{[9]}$ :

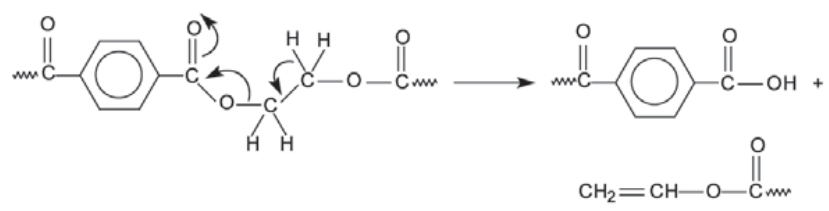

A partir daí, podem ocorrer reações de transesterificação entre os ésteres vinílicos formados e os grupos hidroxílicos terminais, presentes no PET em grande quantidade, gerando álcool vinílico, que é transformado em acetaldeído. Eventualmente, os grupos hidroxílicos terminais podem reagir entre si ou com grupos carboxílicos terminais, regenerando as cadeias de PET e mantendo, dessa forma, um grau de polimerização médio ${ }^{[10,13]}$.

Neste trabalho, foram estudados recobrimentos de poli(tereftalato de etileno) em aço carbono, produzidos com pós obtidos em diferentes condições de moagem, usando-se a técnica de aspersão térmica a combustão.

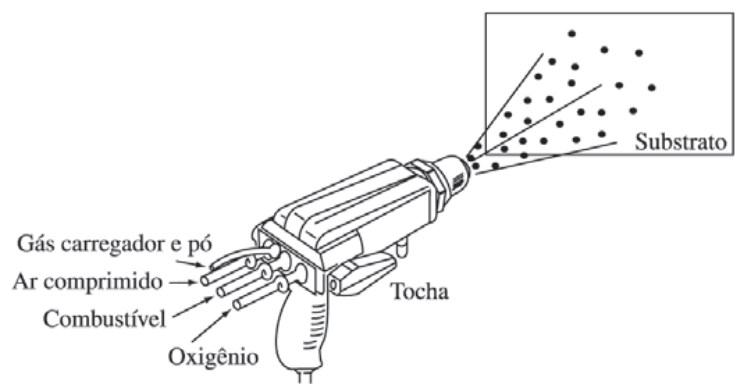

Figura 1. Representação esquemática de um sistema de aspersão a combustão.

\section{Experimental}

\section{Produção e classificação do pó de PET}

Uma parcela do pó de PET utilizado na produção dos recobrimentos foi cedida pela empresa Recipet, sendo proveniente do refugo fino da moagem de garrafas pós-consumo. O pó recebido foi submetido a peneiramento vibratório para obtenção de um material com diâmetro médio de partículas inferior a 65 mesh $(210 \mu \mathrm{m})$, adequado para seu emprego na tocha de aspersão térmica. Foram também utilizados pós oriundos de moagem, em moinho de bolas, de garrafas de refrigerante pós-consumo, as quais foram separadas por coloração, lavadas, cortadas e fundidas. Este material foi então submetido a uma etapa de britagem, efetuada em batelada, realizada em britador de rolos de ferro. No caso do primeiro teste de moagem não foi realizada a etapa prévia de britagem. Após esta etapa, foi feito um peneiramento manual da massa britada, utilizando-se uma peneira de malha 5 mesh $(4 \mathrm{~mm})$. A fração retida foi retornada ao britador. O procedimento foi repetido até se obter cerca de $90 \%$ das partículas abaixo de 4 $\mathrm{mm}$.

A etapa de moagem foi realizada em moinho de porcelana, com 10,5 cm de diâmetro e 12,5 cm de altura, carregado com bolas cerâmicas, as quais perfaziam, aproximadamente, dois terços do volume total do moinho. A Tabela 1 apresenta as condições empregadas nos testes de moagem e a Tabela 2 especifica a carga de bolas usada nos testes. A razão massa de PET/massa total da carga foi de $1 / 6$, sendo a massa de PET alimentada no moinho de $500 \mathrm{~g}$.

A massa de material moído retirada periodicamente do moinho foi determinada, sendo submetida a um peneiramento vibratório para a classificação granulométrica. Somente a faixa granulométrica abaixo de 65 mesh $(210 \mu \mathrm{m})$ foi empregada nos testes de deposição, em função da sua fluidez adequada. $\mathrm{O}$ pó classificado acima desta faixa retornava ao moinho, mantendo-se a mesma carga de bolas.

As modificações nos procedimentos de moagem, conforme mostrado na Tabela 1 , foram introduzidas com o objetivo de aumento do rendimento do processo e obtenção de pós com diferentes morfologias. Nos testes de moagem 1, 2 e 3, sem reposição de alimentação, a razão da carga de PET para a carga de bolas do moinho não se manteve constante ao longo do teste de moagem. No teste 3 tentou-se manter 
Tabela 1. Condições empregadas nos testes de moagem.

\begin{tabular}{|c|c|c|}
\hline $\begin{array}{l}\text { Número } \\
\text { do teste }\end{array}$ & $\begin{array}{l}\text { Temperatura } \\
\text { de fusão }\left({ }^{\circ} \mathrm{C}\right)\end{array}$ & Condições de moagem \\
\hline 1 & 350 & $\begin{array}{l}\text { Carga não britada,sem } \\
\text { reposição de alimentação }\end{array}$ \\
\hline 2 & 350 & $\begin{array}{l}\text { Carga britada, sem } \\
\text { reposição de alimentação }\end{array}$ \\
\hline 3 & 340 & $\begin{array}{c}\text { Moagem criogênica, carga } \\
\text { britada, sem reposição } \\
\text { de alimentação }\end{array}$ \\
\hline 4 & 290 & $\begin{array}{l}\text { Carga britada, com } \\
\text { reposição de alimentação }\end{array}$ \\
\hline
\end{tabular}

Tabela 2. Especificação da carga de bolas utilizada nos testes de moagem de PET.

\begin{tabular}{ccc}
\hline Diâmetro $(\mathbf{m m})$ & Número de bolas & Massa total $(\mathbf{g})$ \\
\hline 25,0 & 44 & 1328,4 \\
18,0 a 20,0 & 116 & 1480,7 \\
15,0 a 16,0 & 45 & 314,0 \\
\hline
\end{tabular}

essa razão constante, pela reposição no moinho de uma massa de PET britado equivalente à massa de pó produzido após um certo intervalo de tempo. No teste 3 , foi realizada uma moagem criogênica, em batelada, usando-se nitrogênio líquido para o resfriamento dos pós, procedimento usual na produção de pós poliméricos ${ }^{[14]}$.

\section{Produção dos recobrimentos}

Os recobrimentos de PET foram depositados em peças retangulares de aço carbono 1020, com dimensões de $2,5 \mathrm{~cm} \times 10 \mathrm{~cm}$. Todos os substratos foram submetidos a jateamento abrasivo com granalha antes da deposição do polímero. Para o processo de aspersão foi empregada uma tocha à combustão subsônica do tipo Diamond Jet, produzida pela METCO Perkin-Elmer.

Os parâmetros da alimentadora de pó do sistema foram ajustados de forma a se obter um jato de pó não pulsante, tendo-se utilizado nitrogênio como gás de arraste, a uma pressão de 100 psi, e ar comprimido, para o vibrador, a 80 psi. Nestas condições, a taxa média de alimentação de pó obtida foi de $0,16 \mathrm{~g} / \mathrm{s}$.

A pressão e o fluxo de ar alimentados na tocha foram mantidos constantes, iguais a 80 psi e $10 \mathrm{~m}^{3} / \mathrm{h}$, respectivamente. A vazão de propano foi de $0,037 \mathrm{~m}^{3} / \mathrm{h}$ e a de oxigênio, $0,17 \mathrm{~m}^{3} / \mathrm{h}$, correspondendo a uma falta de oxigênio de $35 \%$. Nestas condições, o comprimento da chama foi de $30 \mathrm{~cm}$, a temperatura da chama, $1200{ }^{\circ} \mathrm{C}$. Foi feito um préaquecimento do substrato, até a temperatura de $215^{\circ} \mathrm{C}$. Na literatura, recobrimentos de PET foram depositados em substratos de aço pré-aquecidos a $100^{\circ} \mathrm{C}^{[7]}$, e recobrimentos de poli(metacrilato ácido de metila) foram produzidos a uma temperatura de pré-aquecimento apenas $10^{\circ} \mathrm{C}$ menor que a temperatura de fusão do polímero ${ }^{[5]}$. A temperatura escolhida neste trabalho foi de $170{ }^{\circ} \mathrm{C}$, intermediária entre $\mathrm{T}_{\mathrm{g}}$ e $\mathrm{T}_{\mathrm{f}}$, que promoveria uma maior taxa de cristalização do PET. Entretanto, os recobrimentos depositados a uma temperatura de pré-aquecimento do substrato de $170{ }^{\circ} \mathrm{C}$ apresentaram uma rugosidade superficial de $3 \mu \mathrm{m}$. A temperatura de pré-aquecimento do substrato foi, então, aumentada para $215^{\circ} \mathrm{C}$, e os recobrimentos produzidos apresentaram uma rugosidade de $1,5 \mu \mathrm{m}$.

\section{Caracterização química e morfológica do pó de PET e dos recobrimentos}

Para a análise dos espectros na região do infravermelho foram retiradas amostras da garrafa, da massa de PET fundida, dos pós produzidos e do pó da Recipet, assim como dos recobrimentos depositados, tendo sido preparadas pastilhas de $\mathrm{KBr}$. As análises foram conduzidas no espectrômetro de infravermelho, da marca Perkin Elmer, modelo 1760X.

Os experimentos de análise térmica foram realizados em um equipamento da marca Shimadzu, modelo DSC-50, sendo as curvas obtidas empregadas na determinação das temperaturas de transição vítrea $\left(\mathrm{T}_{\mathrm{g}}\right)$, cristalização $\left(\mathrm{T}_{\mathrm{c}}\right)$, fusão $\left(\mathrm{T}_{\mathrm{f}}\right) \mathrm{e}$ degradação $\left(\mathrm{T}_{\mathrm{d}}\right)$ do PET. O grau de cristalinidade das amostras, $\chi_{c}$, foi avaliado a partir do pico endotérmico de fusão, através da seguinte relação ${ }^{[15]}$ :

$$
\chi_{c}=\frac{\Delta \mathrm{H}_{\mathrm{f}}}{\Delta \mathrm{H}_{\mathrm{f}}^{0}}
$$

Onde, $\Delta \mathrm{H}_{\mathrm{f}}$ é a entalpia de fusão da amostra,

$\Delta \mathrm{H}_{\mathrm{f}}{ }^{0}$ é a entalpia de fusão do polímero $100 \%$ cristalino, a qual, no caso do PET, vale $122 \mathrm{~J} / \mathrm{g}^{[15]}$.

As análises de DSC foram conduzidas em células de alumínio abertas, sob atmosfera de gás nitrogênio, alimentado a $20 \mathrm{~mL} / \mathrm{min}$, sendo a varredura feita na faixa de temperatura de $20{ }^{\circ} \mathrm{C}$ a $500{ }^{\circ} \mathrm{C}$. A taxa de aquecimento, ajustada a partir de corridas preliminares, foi de $20{ }^{\circ} \mathrm{C} / \mathrm{min}$. Todas as corridas foram feitas com uma massa de PET em torno de $5 \mathrm{mg}$, tendo-se utilizado uma célula de alumínio vazia como referência.

As alterações de massa molar do PET, devido à ocorrência de degradação térmica, foram investigadas por determinação da viscosidade intrínseca de soluções deste polímero, segundo a norma ASTM D4603-91. As medidas foram realizadas em viscosímetro capilar Ubbelohde Tipo 1B, imerso em banho de etanol (OPTHERM), a uma temperatura de $30{ }^{\circ} \mathrm{C}$. O valor da viscosidade intrínseca foi calculado através dos valores de tempo de fluxo, segundo a relação de Billmeyer, dada abaixo:

$$
\mathrm{VI}=\frac{0,25 \cdot\left(\eta_{\mathrm{r}}-1+3 \cdot \ln \eta_{\mathrm{r}}\right)}{\mathrm{C}}
$$

Onde, VI é a viscosidade intrínseca, em $\mathrm{dL} / \mathrm{g}$,

C é a concentração da solução, em g/dL,

$\eta_{\mathrm{r}}$ é a viscosidade relativa, igual à razão entre o tempo de fluxo da solução polimérica de concentração C e o tempo de fluxo do solvente puro.

Amostras de pó e dos recobrimentos foram avaliadas por microscopia óptica, MO, (Leitz Wetzlar) e eletrônica de var- 
redura, MEV, (JEOL, modelo JSM 35C). As amostras de recobrimento foram embutidas em resina epóxi (Epofix Struers), com cura a frio.

\section{Resultados e Discussões}

\section{Produção do pó de PET}

A morfologia do pó fornecido pela Recipet está apresentada na Figura 2(a). Conforme se observa, as partículas tendem a um formato longitudinal, em forma de bastão, podendo-se notar que a distribuição de tamanho de partículas não é homogênea. A Figura 2(b) é uma fotomicrografia, em lupa, deste mesmo pó aspergido nas condições empregadas para a produção dos recobrimentos. Pode-se verificar que, dada a irregularidade de distribuição de tamanho de partículas desse pó, as menores fundem-se completamente, ao passo que aquelas maiores só apresentam fusão nas bordas. As partículas fundidas mostraram-se como "splats" devido à alta velocidade com que foram projetadas contra a lâmina.

As características morfológicas dos pós produzidos nos testes de moagem 2, 3 e 4 podem ser visualizadas na Figura 3. Esta figura não mostra a fotomicrografia do pó produzido no primeiro teste, desde que suas características foram bastante similares àquelas apresentadas pelo pó produzido no segundo teste.

Conforme pode ser observado, as partículas do pó de PET produzido no segundo teste se apresentam longitudinais ou esféricas, sem variações significativas nos seus tamanhos. Por outro lado, as partículas provenientes do pó gerado em condições criogênicas, teste 3 , têm formas diferentes daquelas observadas no pó da moagem 2 , mostrandose com formas lamelares, tipo lascas. Já o pó gerado na moagem 4 tem uma distribuição de tamanho de partículas mais larga, apresentando também partículas com formatos mais irregulares, em relação aos demais testes.

\section{Produção dos recobrimentos}

A Figura 4 mostra fotomicrografias, em MO, das seções transversais dos recobrimentos de PET depositados a partir do pó fornecido pela Recipet, Figura 4(a), bem como do recobrimento produzido a partir do pó obtido no teste de moagem 3, Figura 4(b), cuja estrutura é similar àquelas apresentadas pelos recobrimentos produzidos a partir dos pós obtidos nos testes de moagem 1, 2 e 4 . Assim, a análise da estrutura dos recobrimentos, usando-se microscopia óptica, não evidenciou diferenças entre os recobrimentos obtidos com os pós oriundos dos quatro testes de moagem em moinho de bolas, embora as características morfológicas dos pós fossem diferentes.

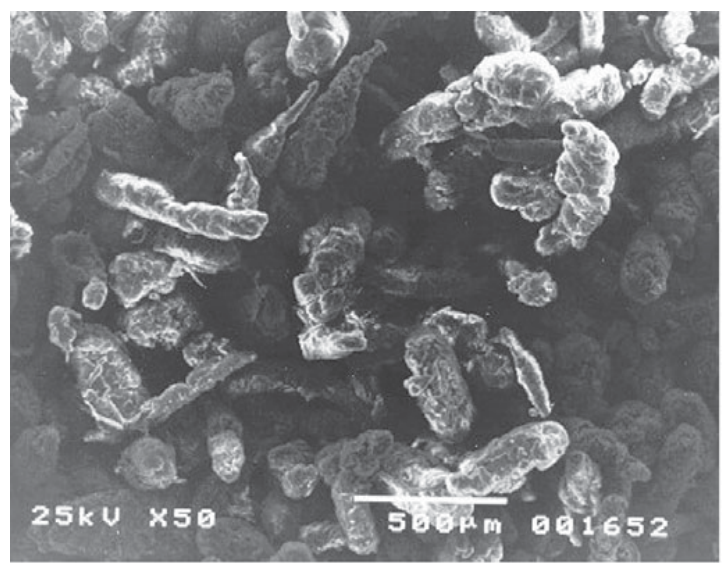

a)

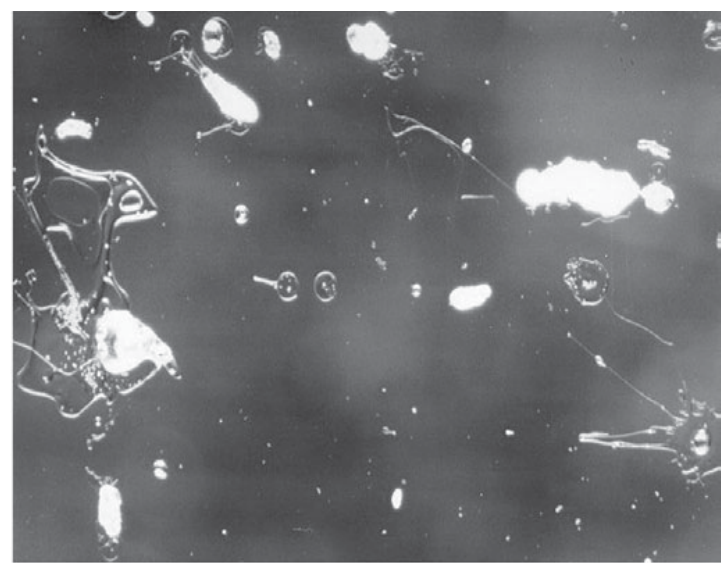

b)

Figura 2. Fotomicrografia do pó de PET fornecido pela Recipet (a), aumento de $50 \times(\mathrm{MEV})$, e deste mesmo pó aspergido em lâmina de vidro (b), aumento de $20 \times$ (lupa)

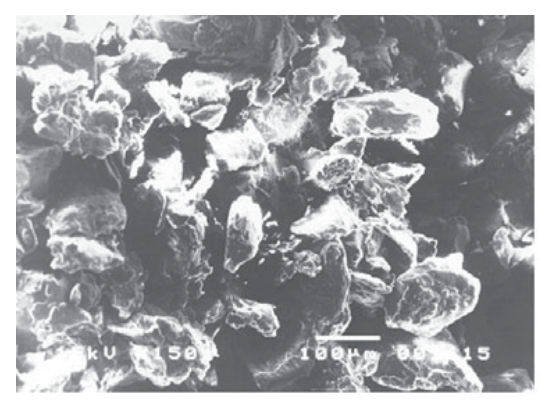

a)

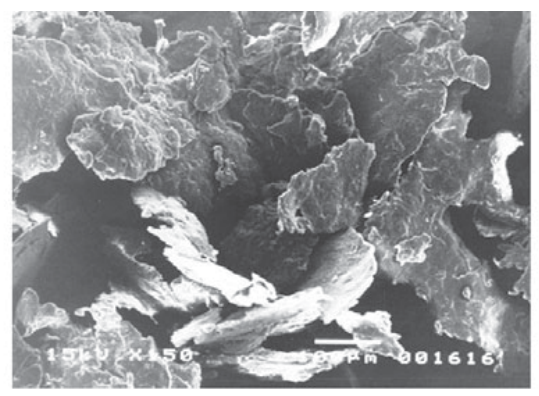

b)

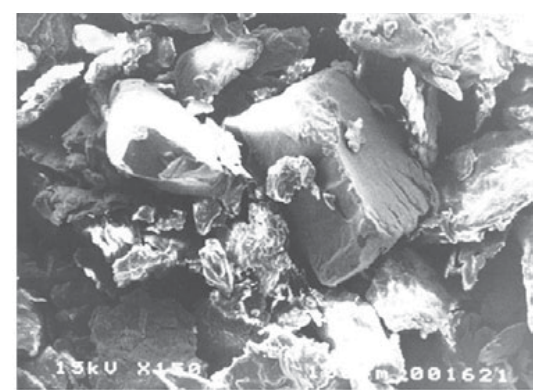

c)

Figura 3. Fotomicrografias em MEV dos pós de PET produzidos nos testes de moagem: (a) teste 2, (b) teste 3 e (c) teste 4 . Aumento de $150 \times$. 
O recobrimento depositado com o pó fornecido pela Recipet apresentou uma estrutura lamelar, com formas muito semelhantes às do pó de PET, sendo possível também a visualização de bolhas. Tais observações sugerem que as partículas depositadas inicialmente no substrato, em um estado não fundido ou semi-fundido, recebem o calor gerado durante o processo de aspersão, provocando fusão e coalescência das mesmas. A formação das bolhas observadas nos recobrimentos foi atribuída à liberação de produtos gasosos decorrentes de reações de degradação do polímero. Tal hipótese foi também utilizada por Brogan para explicar o surgimento de bolhas em recobrimentos poliméricos de PMMA e PMMA/PCCP ${ }^{[5]}$. Uma outra hipótese seria a de que as bolhas poderiam ser geradas pelo ar aprisionado durante a coalescência das partículas.

Os recobrimentos obtidos com os pós oriundos da moagem em laboratório apresentaram também um acentuado número de bolhas, assim como a presença de trincas ligando o substrato com a superfície externa. Por outro lado, não se verificou a constituição de recobrimentos com estruturas lamelares.

Os formatos das partículas presentes nos pós produzidos por moagem em moinho de bolas eram mais regulares que aqueles do pó da Recipet. Além disto, a distribuição de tamanho era mais homogênea. Desta forma, seria esperada uma fusão das partículas deste pó durante o tempo de residência na chama, o que é compatível com a inexistência de uma estrutura lamelar, visível ao microscópio óptico. Este maior grau de fusão das partículas durante o tempo de residência na chama foi verificado a partir da aspersão dos pós em lâminas de vidro temperado. As fotomicrografias das lâminas contendo os pós produzidos nos testes de moagem 2 e 3 estão mostradas na Figura 5.

Nos testes de deposição com os pós produzidos nos testes de moagem em moinho de bolas, observou-se que as trincas se formavam logo após o resfriamento do recobrimento. Esta ocorrência não foi notada durante a produção dos recobrimentos com o pó da Recipet. Além disto, as trincas eram grandes e surgiam em diversos pontos. Neste caso, levantou-se a hipótese de que os pós de moagem apresenta-

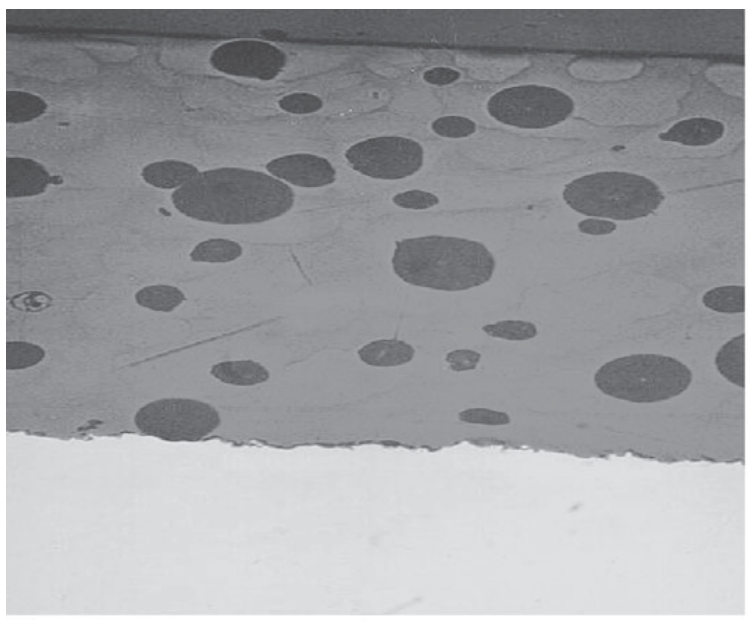

a)

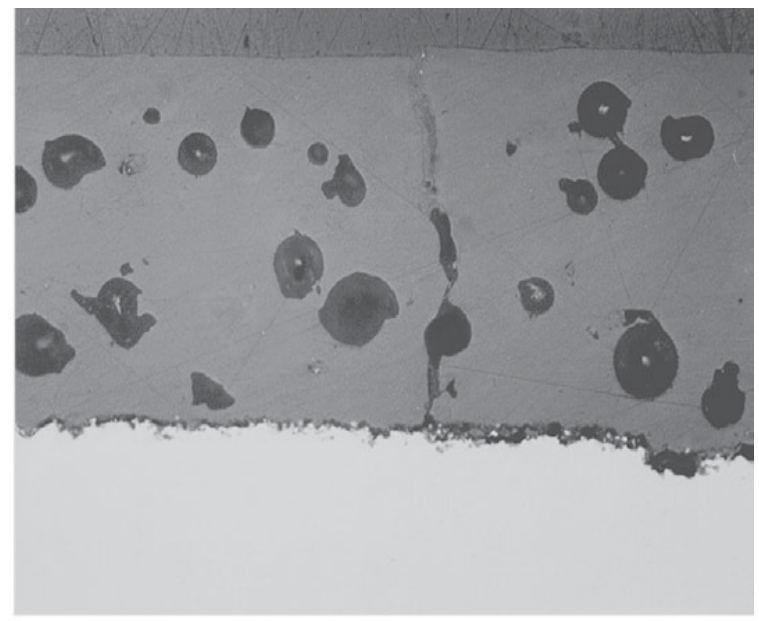

b)

Figura 4. Fotomicrografias, em MO, das seções transversais dos recobrimentos de PET produzidos a partir: (a) do pó fornecido pela Recipet, (b) do pó produzido na moagem 3. Aumento de 100x.

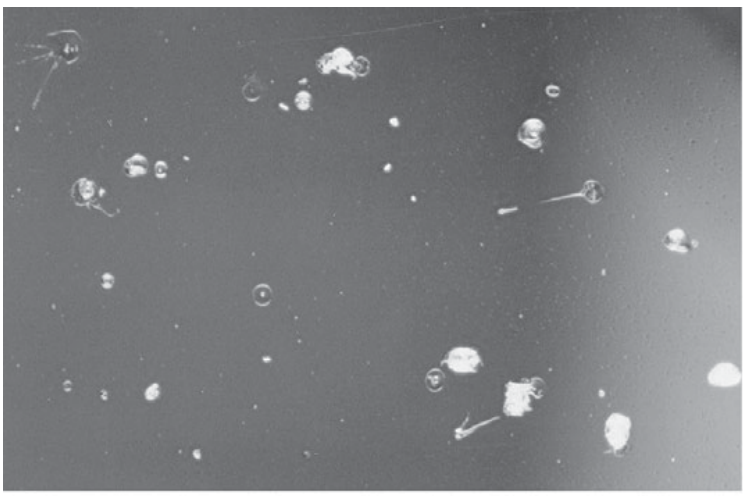

a)

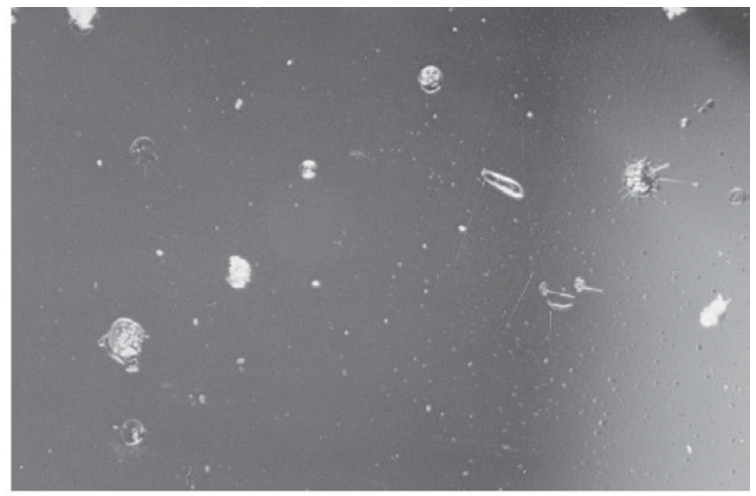

b)

Figura 5. Fotomicrografias, em lupa, das lâminas contendo os pós aspergidos em lâminas de vidro: (a) pó produzido no teste de moagem 3, (b) pó produzido no teste de moagem 4 . Aumento de $20 x$. 
vam-se fragilizados devido à etapa anterior de fusão, a qual levou à ocorrência de degradação térmica, com quebra das cadeias poliméricas e conseqüente alteração das propriedades mecânicas do material.

\section{Caracterização dos pós e dos recobrimentos}

Os espectros de FTIR obtidos para o pó da Recipet, para os pós produzidos nos testes de moagem, bem como para os recobrimentos de PET foram comparados com o espectro de PET puro, publicado por Hummel ${ }^{[16]}$, tendo-se verificado que as amostras analisadas apresentaram bandas de absorção nos mesmos comprimentos de onda deste último. Também não foi constatado desaparecimento ou surgimento de bandas decorrentes do processo de aspersão, o que indica a manutenção da estrutura química do polímero durante os processos de fusão, moagem das garrafas e deposição dos recobrimentos.

A Tabela 3 apresenta uma síntese dos resultados obtidos por análise térmica e aqueles provenientes dos ensaios para determinação de viscosidade intrínseca em soluções das amostras de PET.

As temperaturas de transição vítrea obtidas situaram-se na faixa entre $71{ }^{\circ} \mathrm{C} \mathrm{e} 79^{\circ} \mathrm{C}$. Os pós produzidos por moagem em

Tabela 3. Resultados obtidos por análise térmica e por determinação de viscosidade em solução.

\begin{tabular}{|c|c|c|c|c|c|}
\hline Amostra & $\mathbf{T}_{\mathrm{g}}\left({ }^{\circ} \mathbf{C}\right)$ & $\mathbf{T}_{\mathrm{f}}\left({ }^{\circ} \mathbf{C}\right)$ & $\mathbf{T}_{d}\left({ }^{\circ} \mathbf{C}\right)$ & $\chi_{\mathrm{c}}(\%)$ & $\overline{V I}(\mathrm{dL} / \mathrm{g})$ \\
\hline Garrafa & 76 & 247 & 434 & 24 & 0,78 \\
\hline $\begin{array}{c}\text { Placa } \\
\text { fundida } \\
\left(350^{\circ} \mathrm{C}\right)\end{array}$ & 74 & 247 & 432 & 25 & 0,36 \\
\hline $\begin{array}{l}\text { Placa } \\
\text { fundida } \\
\left(340^{\circ} \mathrm{C}\right)\end{array}$ & 74 & 247 & 433 & 26 & 0,38 \\
\hline $\begin{array}{l}\text { Placa } \\
\text { fundida } \\
\left(290^{\circ} \mathrm{C}\right)\end{array}$ & 75 & 247 & 433 & 24 & 0,37 \\
\hline $\begin{array}{l}\text { Pó da } \\
\text { Recipet }\end{array}$ & 77 & 243 & 444 & 41 & 1,04 \\
\hline $\begin{array}{l}\text { Pó moa- } \\
\text { gem } 1\end{array}$ & 72 & 247 & 442 & 31 & 0,40 \\
\hline $\begin{array}{l}\text { Pó moa- } \\
\text { gem } 2\end{array}$ & 71 & 247 & 438 & 32 & 0,41 \\
\hline $\begin{array}{l}\text { Pó moa- } \\
\text { gem } 3\end{array}$ & 72 & 247 & 443 & 32 & 0,40 \\
\hline $\begin{array}{l}\text { Rec. pó } \\
\text { Recipet }\end{array}$ & 75 & 245 & 445 & 21 & 0,48 \\
\hline $\begin{array}{c}\text { Rec. } \\
\text { pó moa- } \\
\text { gem } 1\end{array}$ & 71 & 247 & 439 & 27 & 0,35 \\
\hline $\begin{array}{l}\text { Rec. } \\
\text { pó moa- } \\
\text { gem } 2\end{array}$ & 74 & 247 & 445 & 27 & 0,37 \\
\hline $\begin{array}{l}\text { Rec. } \\
\text { pó moa- } \\
\text { gem } 3\end{array}$ & 75 & 247 & 445 & 28 & 0,34 \\
\hline
\end{tabular}

moinho de bolas apresentaram menores valores de $\mathrm{T}_{\mathrm{g}}$ em relação ao pó da Recipet devido ao fato de já apresentarem degradação devido à etapa de fusão das garrafas. Os recobrimentos produzidos com o pó obtido da moagem em moinho de facas apresentaram valores de $\mathrm{T}_{\mathrm{g}}$ similares aos do pó.

Os recobrimentos produzidos com os pós de moagem em moinho de bolas tiveram seus valores de $\mathrm{T}_{\mathrm{g}}$ relativamente próximos aos das placas fundidas. Isto sugere que, durante o processo de fusão, houve degradação térmica do PET, sendo que o grau de degradação alcançado já permitia a ocorrência de reações entre os grupos terminais hidroxílicos e ácidos carboxílicos terminais. Portanto, o pó obtido já estava degradado e, ao passar pelo aquecimento gerado no processo de aspersão, o polímero continuou a sofrer degradação, porém a uma taxa menor. Os pós produzidos nas diferentes condições de moagem apresentaram o mesmo valor para a $\mathrm{T}_{\mathrm{g}}$.

Os valores diferentes das $\mathrm{T}_{\mathrm{g}}$ 's dos pós produzidos por moagem, em relação à placa e ao recobrimento, podem ser devido ao fato de as amostras na forma de pó terem uma área superficial para troca de calor maior, apresentando, então, uma $\mathrm{T}_{\mathrm{g}}$ menor, já que a resposta ao fluxo de calor será mais rápida. Entretanto, esta diferença entre os valores da $\mathrm{T}_{\mathrm{g}}$ dos pós e a da $\mathrm{T}_{\mathrm{g}}$ dos recobrimentos e das placas foi de $2{ }^{\circ} \mathrm{C}^{\mathrm{g}}$ a $3{ }^{\circ} \mathrm{C}$, muito próxima do valor do erro do equipamento, de $1,5^{\circ} \mathrm{C}$.

Não foram observadas grandes diferenças entre os valores da temperatura de fusão, que se situou na faixa de 244 a $247{ }^{\circ} \mathrm{C}$, e da temperatura de degradação, cujo valor médio foi de $439{ }^{\circ} \mathrm{C}$. Tais valores são coerentes com os dados apresentados na literatura ${ }^{[17]}$, e também mostram que, embora algumas amostras tenham sofrido degradação, elas ainda mantiveram a estrutura química característica do PET.

Os valores registrados para a fração cristalizada do PET se situaram entre 21 e $41 \%$, podendo-se observar que o recobrimento do pó da Recipet apresentou um valor de $\chi_{\mathrm{c}}$ menor que o pó utilizado. Isto está coerente com o fato de que os cristais de PET são desfeitos durante a fusão, sendo que as cadeias se reorganizam em uma outra estrutura, menos cristalina, enquanto o polímero resfria e se solidifica. A quantidade de cristal formado, ou seja, o grau de cristalinidade do recobrimento depositado, vai depender da taxa de resfriamento, do tamanho das cadeias poliméricas e da cinética de cristalização do material. A fração cristalizada de PET dos recobrimentos obtidos com os pós do processo de moagem em moinho de bolas também foi inferior à fração cristalizada de PET dos respectivos pós.

Por outro lado, os recobrimentos produzidos com pó de moagem em moinho de bolas apresentaram um $\chi_{c}$ ligeiramente maior que o valor para as placas fundidas, cuja explicação pode ser a mesma dada para a $\mathrm{T}_{\mathrm{g}}$. A comparação direta, na análise por DSC, com o pó torna-se complicada pelas formas físicas diferentes deste e das placas fundidas. Podese supor, também, que a taxa de resfriamento do polímero quando da produção das placas fosse superior à taxa de resfriamento dos recobrimentos. Os pós oriundos dos quatro testes de moagem em moinho de bolas apresentaram praticamente o mesmo valor da fração cristalizada de PET.

Em se tratando dos resultados de viscosidade intrínseca, 
observa-se uma redução, aproximadamente pela metade, dos valores desse parâmetro, ao se comparar o recobrimento e o pó de PET fornecido pela Recipet, apontando para uma degradação térmica do polímero decorrente da deposição por aspersão térmica. A viscosidade intrínseca dos recobrimentos depositados com os pós obtidos da moagem em moinho de bolas também foi inferior à viscosidade intrínseca dos respectivos pós. Entretanto, esta diferença de viscosidade não foi tão significativa quanto no caso anterior, observado para os recobrimentos feitos com o pó da Recipet, devido ao fato do pó já se apresentar degradado em virtude da etapa prévia de fusão das garrafas. Quanto maior a viscosidade intrínseca (VI) inicial, maior a diminuição da VI durante o processamento. Não foi observada uma diferença de viscosidade intrínseca entre os pós produzidos nas diferentes condições de moagem. Foi observada a redução da viscosidade intrínseca do polímero durante a etapa de fusão das garrafas de PET, evidenciando a degradação ocorrida. Comparando-se os resultados da viscosidade das placas fundidas e dos recobrimentos produzidos, observa-se, no caso do pó produzido através de moagem criogênica, uma pequena redução no valor da viscosidade após o processo de aspersão térmica. Provavelmente, a degradação do polímero continua durante o processo de aspersão, mas a uma taxa menor, conforme já mencionado.

\section{Conclusões}

Verificou-se que é possível a produção de recobrimentos de PET por aspersão térmica a combustão.

Os recobrimentos produzidos com os pós obtidos através da moagem em moinho de bolas e de facas apresentaram diferenças identificadas por meio das técnicas utilizadas de caracterização dos recobrimentos. Os recobrimentos produzidos com os pós oriundos da moagem em moinho de bolas apresentaram trincas ligando o substrato com a superfície externa e um acentuado número de bolhas, além da ausência da estrutura lamelar observada nos recobrimentos obtidos com os pós da moagem em moinho de facas. A presença de bolhas foi observada em todos os recobrimentos produzidos neste trabalho.

As técnicas de análise empregadas para a caracterização do PET nas diversas etapas do trabalho indicaram que o polímero sofreu degradação durante o processo de fusão e aspersão térmica. Além disto, a degradação observada deve ser devido, principalmente, à quebra térmica das cadeias.

Os resultados obtidos também reforçaram a hipótese de que a degradação térmica do PET tende a um estágio no qual o tamanho das cadeias e, em conseqüência, a massa molar do polímero, são reduzidos a taxas mais baixas, devido à ocorrência de reações entre os grupos hidroxílicos e ácidos carboxílicos terminais formados nos mecanismos de quebra das cadeias.

Alterações químicas e estruturais do PET decorrentes da etapa de moagem não ocorreram, ou se processaram em pequena extensão.

Os resultados de análise térmica mostraram alterações do grau de cristalinidade do PET sempre que este polímero era fundido e resfriado, quer na etapa de produção do pó, quer no processo de aspersão.

\section{Agradecimentos}

Os autores agradecem ao Eng. Marcelo Maciel, pela ajuda e preciosas sugestões no decorrer do trabalho. Agradecem também à Capes e à Fapemig pelo auxílio financeiro.

\section{Referências bibliográficas}

1. Branco, J.R.T.; Campos, S.V. Surf.Coat.Tech.,120-121, p. 476, 1999.

2. Han, W.; Rybicki, E.F.; Shadley, J.R. J. Therm. Spray Technol., 2, 2, p.145, 1993.

3. Plástico Moderno 266, 8-18, 1996.

4. Zhang, T.; Gawne, D.T.; Bao, Y. Surf. Coat. Tech., 96, p.337, 1997.

5. Brogan, J.A. Processing and Property Relationships of Thermally Sprayed Polymer Systems, PhD Thesis, State University of New York at Stony Brook, USA, 1996.

6. Brogan, J.A.; Berndt, C.C.; Claudon, A.; Coddet, C. The Mechanical Properties of Combustion-Sprayed Polymers and Blends, in: Thermal Spray: Pratical Solutions for Engineering Problems, Edited by C. C. Berndt, ASM International, Ohio, p.221-226, 1996.

7. Lima, R.S.; Takimi, A.S.; Lima, M.D.; Bergmann, C.P.; Ferreira, C.A.; Neto, R.B.; Branco, J.R.T. Produção de Revestimentos de Polietileno Tereftalato (PET) Reciclado por Aspersão Térmica, in: Anais do Congresso Latino-Americano de Acabamento INTERFINISH 1997, São Paulo, 1997.

8. Allen, N.S.; Edge, M.; Mohammadian, M. Europ. Polym. $J ., 27$, n.12, p.1373, 1991.

9. Fann, D.; Huang, S.K.; Lee, J. J. Appl. Polym. Sci., 61, n. 8, p. 261, 1996.

10. Tate, S.; Narusawa, H. Polym., 37, n. 9, p.1583, 1996.

11. Calleja, F.J.B.; Cagiao, M.E.; Zachmann, H.G.; Vanderdoncckt, C. J. Macromol. Sci.-Phys., 33, p. 333, 1994.

12. Launay, A.; Thominette, F.V. J. Polym. Degrad. and Stab., 46, n.3, p.319, 1994.

13. Edge, M.; Wiles, R.; Allen, N. S.; McDonald, W. A.; Mortlock, S.V. Polym. Degrad. Stab., 53, p. 141, 1996.

14. Prutt, E. V. - Polym. Scienc. , 36, n. 4, p. 493, 1994).

15. Okamoto, M.; Shinoda, Y.; Kinami, N.; Okuyama, T. J. of Appl. Polym. Sci., 57, p.1055, 1995.

16. Hummel, D.O. Atlas of Polymer and Plastics Analysis I. Polymers: Structures and Spectra. 2르. edition. Weinheim: VCH Verlogsgesellschaft, 1985.

17. Brandrup, J.; Immergut, E.H. Polymer Handbook, John Willey \& Sons Inc., New York, 1989.

Recebido: 20/11/02

Aprovado: 11/06/03 